\title{
Top-down gain control of the auditory space map by gaze control circuitry in the barn owl
}

\author{
Daniel E. Winkowski ${ }^{1}$ and Eric I. Knudsen ${ }^{1}$ \\ 1Department of Neurobiology, Stanford University, Stanford, California 94305, USA
}

\begin{abstract}
High-level circuits in the brain that control the direction of gaze are intimately linked with the control of visual spatial attention ${ }^{1-5}$. Immediately before an animal directs its gaze towards a stimulus, both psychophysical sensitivity to that visual stimulus and the responsiveness of high-order neurons in the cerebral cortex that represent the stimulus increase dramatically $3,6,7$. Equivalent effects on behavioural sensitivity and neuronal responsiveness to visual stimuli result from focal electrical microstimulation of gaze control centres in monkeys ${ }^{8-11}$. Whether the gaze control system modulates neuronal responsiveness in sensory modalities other than vision is unknown. Here we show that electrical microstimulation applied to gaze control circuitry in the forebrain of barn owls regulates the gain of midbrain auditory responses in an attention-like manner. When the forebrain circuit was activated, midbrain responses to auditory stimuli at the location encoded by the forebrain site were enhanced and spatial selectivity was sharpened. The same stimulation suppressed responses to auditory stimuli represented at other locations in the midbrain map. Such space-specific, top-down regulation of auditory responses by gaze control circuitry in the barn owl suggests that the central nervous system uses a common strategy for dynamically regulating sensory gain that applies across modalities, brain areas and classes of vertebrate species. This approach provides a path for discovering mechanisms that underlie top-down gain control in the central nervous system.
\end{abstract}

The possibility that gaze control circuitry mediates spatial attention for audition, as well as for vision, is suggested by psychophysical and neurophysiological data. For example, when human subjects are asked to report the relative location of a short-duration, pulsed white noise stimulus, reaction time decreases and accuracy improves when the auditory stimulus is located near the endpoint of a visually instructed eye saccade compared to when saccades are made in the opposite direction ${ }^{12}$. In addition, responses of auditory neurons in the substantia nigra and caudate nucleus of monkeys increase when an auditory stimulus is the target of an upcoming eye saccade ${ }^{13,14}$.

In this study, we tested the hypothesis that forebrain gaze control circuitry regulates auditory neural processing in a space-specific manner. The arcopallial gaze fields (AGF), a premotor region in the owl's forebrain, has a central role in the control of gaze direction 15 . This region is analogous to the frontal eye fields (FEF) in the mammalian frontal cortex. The AGF, like the FEF, projects in parallel to the deep layers of the optic tectum and to saccade-generating premotor neurons in the brainstem ${ }^{16,17}$; electrical microstimulation in the AGF, like in the FEF, produces orienting movements of the eyes and head 16,18 ; and the AGF, like the FEF,

Correspondence and requests for materials should be addressed to D.E.W. (dwinkows@ stanford.edu).

Author Contributions D.E.W. and E.I.K. designed the experiment and co-wrote the paper. D.E.W. carried out the electrophysiological recordings and data analysis.

Reprints and permissions information is available at npg.nature.com/reprintsandpermissions.

The authors declare no competing financial interests. 
mediates memory-guided saccades 19,20 . Recently, the FEF in monkeys has also been shown to direct visual spatial attention and to regulate the responsiveness of extrastriate visual neurons in a space-specific manner ${ }^{9,10}$. A similar role for the AGF has not previously been tested.

In our study, electrical microstimulation was applied to the AGF while auditory responses were measured in the deep layers of the optic tectum, which contains a map of auditory space ${ }^{21}$. Auditory stimuli were presented via earphones so that spatial cues could be presented in randomly interleaved patterns and at high resolution, allowing us to characterize the spatial specificity of any gain changes. To simulate changes in stimulus location, we varied interaural timing differences (ITD), which indicate the horizontal position of a sound stimulus, and interaural level differences (ILD), which for barn owls indicate the vertical position of a stimulus $^{22}$.

The auditory portion of the AGF contains neurons that are tuned for both ITD and ILD and, therefore, for space ${ }^{23}$. Unlike in the optic tectum, where auditory space is mapped, in the AGF space is organized in a clustered representation in which neighbouring neurons encode a similar location, but neighbouring groups of neurons encode different, unpredictable locations ${ }^{23}$. The stimulating microelectrode was positioned in the centre of an AGF cluster as follows. In dorsoventral electrode penetrations through the AGF, ITD and ILD tuning was measured at approximately $100-\mu \mathrm{m}$ intervals. When a cluster was found in which ITD and ILD tuning remained constant ( $\pm 15 \mu$ s and $\pm 4 \mathrm{~dB}$, respectively) for at least $300 \mu \mathrm{m}$, the electrode was centred in the cluster and the binaural tuning at the stimulation site was measured. The threshold for eliciting a motor response was determined by passing balanced biphasic pulses (25-ms train, $200 \mathrm{~Hz}, 200-\mu$ s phase duration) through the electrode and finding the lowest current level that elicited an eye saccade (mean $150 \mu \mathrm{A}$, range 55-400 $\mu \mathrm{A}$ ). During the experiments, current amplitude was set to levels of less than half the threshold for eliciting a motor response and was never increased above $40 \mu \mathrm{A}$.

To monitor auditory responses, a second microelectrode was introduced into the deep layers (layers 11-13) of the optic tectum, and binaural tuning at the recording site was measured. Best ITD and best ILD were defined as the weighted average of responses greater than half of the maximum response (henceforth referred to as 'half-max'). Tuning width was defined as the continuous range of ITD values that elicited a response greater than half-max. On the basis of that tuning, a stimulus set was programmed that sampled the entire ITD range for the site, at 10 - or 20- $\mu$ s intervals (10-20 repetitions of each ITD value under each condition), while holding ILD constant at the site's best value. On half of the trials, the sound was immediately preceded by AGF microstimulation. All ITD values and conditions (with and without electrical microstimulation) were randomly interleaved. In sequential stimulus sets, the AGF microstimulation current was increased in small increments until an effect on auditory responses was observed or until the current level reached $40 \mu \mathrm{A}$ (maximum current tested).

Results from an experiment in which the binaural (spatial) tuning for ITD and ILD at the AGF and optic tectum sites were similar are shown in Fig. 1. For the AGF site, the best ITD was $10 \mu$ s (leading in the left ear) and the best ILD was $1 \mathrm{~dB}$ (greater in the right ear). For the optic tectum site, the best ITD was $-16 \mu \mathrm{s}\left(\triangle \mathrm{ITD}_{\mathrm{AGF}-\mathrm{OT}}=6 \mu \mathrm{s} ; \sim 2^{\circ}\right.$ azimuth) and the best ILD was $1 \mathrm{~dB}\left(\Delta \mathrm{ILD} \mathrm{AGF}_{\mathrm{AT}}=0 \mathrm{~dB}\right)$. Electrical microstimulation $(7 \mu \mathrm{A}, 25-\mathrm{ms}$ train duration, 200 $\mathrm{Hz}$; current to evoke eye saccades was $175 \mu \mathrm{A}$ ) applied to the AGF site just before the onset of the sound stimulus increased the strength of the optic tectum auditory responses to ITDs within $10 \mu$ s of the best ITD (Fig. 1b-d) but had no effect on responses to sounds with ITDs outside of the receptive field (Fig. 1b, c, e). AGF microstimulation caused the best ITD of the optic tectum site to shift dynamically by $4 \mu$ s (best ITD with AGF microstimulation $-12 \mu \mathrm{s}$; $P<0.001$, paired $t$-test) towards the ITD value represented at the AGF site (Fig. 1c, arrows). 
The opposite result was observed in an experiment in which the best ITDs at the AGF and optic tectum sites differed by $45 \mu \mathrm{s}\left(\sim 18^{\circ}\right.$ azimuth; Fig. 2$)$. AGF microstimulation (best ITD -10 $\mu \mathrm{s} ; 7 \mu \mathrm{A})$ suppressed auditory responses, but only when the ITD of the sound was near the best ITD for the optic tectum site (best ITD $-55 \mu \mathrm{s}$ ).

We tested the effects of microstimulation (mean current $14 \mu \mathrm{A}$, range 5-40 $\mu \mathrm{A}$ ) at 41 AGF sites on auditory responses at 95 optic tectum sites. At 55 sites in the optic tectum (8 single units) for which $\Delta \mathrm{ITD}_{\mathrm{AGF}-\mathrm{OT}}$ was $\leq 15 \mu \mathrm{s}$ ( $\leq 6^{\circ}$ azimuth), AGF activation either enhanced auditory responses $(n=45 / 55$ sites; $P<0.05$, paired $t$-test) or had no effect ( $n=10 / 55$ sites) (Fig. 2e). Because sites with such similar $\triangle \mathrm{ITD}_{\mathrm{AGF}-\mathrm{OT}}$ showed a similar effect, we refer to these collectively as 'aligned pairs'. At 40 sites in the optic tectum ( 9 single units) for which $\Delta \mathrm{ITD}_{\mathrm{AGF}-\mathrm{OT}}$ was $>15 \mu \mathrm{s}$, AGF activation either suppressed auditory responses $(n=23 / 40$ sites; $P<0.05$, paired $t$-test) or had no effect ( $n=17 / 40$ sites) (Fig. 2e); we refer to these as 'non-aligned pairs'. Single unit and multi-unit sites produced similar results.

The effect of AGF stimulation on optic tectum responses was summarized by weighted averages of the data from individual sites. Across all 55 aligned pairs of sites (Fig. 3a), responses to best ITD increased by an average of 33\% (range -8 to $105 \%, P<0.0001$, paired $t$-test) and the tuning width at half-max decreased by $16 \%$ (range -48 to $20 \%, P<0.001$, paired $t$-test). AGF microstimulation also tended to shift optic tectum tuning at aligned sites towards the value represented at the AGF stimulation site (Fig. 3b).

In contrast, across all 40 non-aligned pairs of sites (Fig. 3c), responses to best ITD decreased by an average of $16 \%$ (range -48 to $14 \% ; P<0.0001$, paired $t$-test) and tuning width at halfmax did not change significantly (range $-14 \%$ to $19 \%, P=0.065$, paired $t$-test).

The sharpening of auditory tuning curves that resulted from AGF activation is remarkable, because auditory tuning curves measured in the optic tectum under normal conditions are the sharpest of any observed in any part of the brain in any species (average width at half-max 40 $\mu$ s, or $16^{\circ}$ azimuth) $)^{22,24}$. Our results show that with AGF activation, they become even sharper (average width at half-max $32 \mu \mathrm{s}$, or $12^{\circ}$ azimuth). This sharpening is caused by an enhancement of responses specifically to ITDs within $10 \mu \mathrm{s}$ of the best ITD. This modulation of responsiveness that operates selectively within a site's receptive field cannot be accounted for by non-selective gain changes occurring at a stage in the pathway where receptive fields are smaller, as has been suggested to explain analogous effects in extrastriate visual areas 25 , 26 , because auditory receptive fields at earlier stages in this pathway are larger. Thus, this result indicates that a gain control mechanism with extremely high spatial resolution can increase auditory response gain within a portion of the site's receptive field.

AGF activation causes an increase in response gain for the ITDs represented by the AGF site (Fig. 3b). The same AGF activation causes a suppression of responses to auditory stimuli at other locations in space (Fig. 2). The result is a top-down enhancement of the representation of auditory stimuli, selected on the basis of stimulus location by this gaze control circuitry. These effects are similar not only to the microstimulation-induced modulations of visual responses observed in monkeys ${ }^{9}$ (effects that have been linked directly to spatial attention ${ }^{10}$ ) but also to modulations of visual responses observed in animals trained to direct spatial attention ${ }^{27-29}$. Although behavioural experiments will be required to test whether our results in owls are linked to spatial attention, the similarity of the effects of microstimulating forebrain gaze control circuitry in barn owls (on auditory processing) and in monkeys (on visual processing) suggests a common strategy used by the central nervous system for top-down, space-specific control of sensory gain and offers a path for discovering the underlying mechanisms. 


\section{Methods}

\section{Animal preparation and recording}

Twelve barn owls were used for this study. Owls were housed in large communal aviaries. For all surgical procedures, owls were anaesthetized with halothane (1\%) mixed with nitrous oxide and oxygen (45:55 ratio). General surgical and experimental procedures, described in detail previously 30 , were approved by the Animal Care and Use Committee of Stanford University and were in accordance with National Institutes of Health and Society for Neuroscience guidelines.

\section{Microstimulation}

Electrical microstimulation was delivered with a Grass stimulator (S88) and two Grass stimulus isolation units (PSIU-6). Current amplitude was monitored by way of the voltage drop across a $1-\mathrm{k} \Omega$ resistor in series with the return path of the current source. Electrical stimulation was delivered to the AGF site through an epoxy-coated tungsten microelectrode (0.5-1.0M $\Omega$ impedance measured at $1 \mathrm{kHz}$ ). In each bird, the AGF was localized on the basis of protocols and coordinates described previously ${ }^{23}$. During each experimental session, the current threshold to evoke a motor response was determined by incrementally increasing the stimulation current until a small-amplitude eye movement (a small deflection in the position of a retinal landmark, pecten oculus, viewed ophthalmoscopically) was observed. Once the threshold for eliciting a motor response from the AGF site was determined, the amplitude of the experimental current pulses was then set to low levels $(5 \mu \mathrm{A})$ and incrementally increased until either we observed an effect on optic tectum auditory responses or the current amplitude reached $40 \mu \mathrm{A}$ (lowest observed motor threshold $55 \mu \mathrm{A}$ ).

\section{Auditory stimulation}

Auditory tuning was measured by presenting noise bursts (100-ms duration, 4-12 kHz, 0-ms rise/fall time, $20 \mathrm{~dB}$ above unit threshold) dichotically as described previously 22,30 . Tuning for ITD was assessed by presenting 10-20 series of noise bursts with ITD varied in a random, interleaved fashion while ILD was held at the optimal value for the site.

\section{Data analysis}

Unit recordings were collected from 12 owls (number of unit recordings per owl: 8, 5, 6, 10, $6,8,9,6,9,8,11,9)$. Net responses at each optic tectum site were quantified by subtracting the number of spikes that occurred during the 100-ms interval before stimulus presentation (baseline activity) from the number of spikes occurring during the $100 \mathrm{~ms}$ after stimulus (sound) onset. On trials during which microstimulation was applied to the AGF, the stimulation artefact was excluded from the analysis and the baseline spike count was normalized to a 100ms window before the subtraction. Net responses from each trial were then averaged. Paired $t$-tests were used to compare net responses during trials with and without stimulation. The significance of dynamic shifts in the best ITDs of optic tectum sites was tested by comparing 15 independent measurements of best ITD, with and without AGF microstimulation, with a two-tailed paired $t$-test.

\section{Acknowledgements}

We thank J. Bergan, M. Cohen, K. Maczko, T. Moore and I. Witten for reviews of earlier versions of the manuscript, and P. Knudsen for technical assistance. This work was supported by grants from the National Institutes of Health (E.I.K.) and an NRSA postdoctoral fellowship (D.E.W.) 


\section{References}

1. Moore T, Armstrong KM, Fallah M. Visuomotor origins of covert spatial attention. Neuron 2003;40:671-683. [PubMed: 14622573]

2. Rizzolatti G, Riggio L, Dascola I, Umilta C. Reorienting attention across the horizontal and vertical meridians: evidence in favor of a premotor theory of attention. Neuropsychologia 1987;25:31-40. [PubMed: 3574648]

3. Hoffman JE, Subramaniam B. The role of visual attention in saccadic eye movements. Percept Psychophys 1995;57:787-795. [PubMed: 7651803]

4. Shepherd M, Findlay JM, Hockey RJ. The relationship between eye movements and spatial attention. Q J Exp Psychol A 1986;38:475-491. [PubMed: 3763952]

5. Corbetta M. Frontoparietal cortical networks for directing attention and the eye to visual locations: identical, independent, or overlapping neural systems? Proc Natl Acad Sci USA 1998;95:831-838. [PubMed: 9448248]

6. Moore T, Tolias AS, Schiller PH. Visual representations during saccadic eye movements. Proc Natl Acad Sci USA 1998;95:8981-8984. [PubMed: 9671790]

7. Fischer B, Boch R. Enhanced activation of neurons in prelunate cortex before visually guided saccades of trained rhesus monkeys. Exp Brain Res 1981;44:129-137. [PubMed: 7286100]

8. Muller JR, Philiastides MG, Newsome WT. Microstimulation of the superior colliculus focuses attention without moving the eyes. Proc Natl Acad Sci USA 2005;102:524-529. [PubMed: 15601760]

9. Moore T, Armstrong KM. Selective gating of visual signals by microstimulation of frontal cortex. Nature 2003;421:370-373. [PubMed: 12540901]

10. Moore T, Fallah M. Microstimulation of the frontal eye field and its effects on covert spatial attention. J Neurophysiol 2004;91:152-162. [PubMed: 13679398]

11. Cavanaugh J, Wurtz RH. Subcortical modulation of attention counters change blindness. J Neurosci 2004;24:11236-11243. [PubMed: 15601929]

12. Rorden C, Driver J. Does auditory attention shift in the direction of an upcoming saccade? Neuropsychologia 1999;37:357-377. [PubMed: 10199648]

13. Hikosaka O, Wurtz RH. Visual and oculomotor functions of monkey substantia nigra pars reticulata. I. Relation of visual and auditory responses to saccades. J Neurophysiol 1983;49:1230-1253. [PubMed: 6864248]

14. Hikosaka O, Sakamoto M, Usui S. Functional properties of monkey caudate neurons. II. Visual and auditory responses. J Neurophysiol 1989;61:799-813. [PubMed: 2723721]

15. Knudsen EI, Knudsen PF. Contribution of the forebrain archistriatal gaze fields to auditory orienting behaviour in the barn owl. Exp Brain Res 1996;108:23-32. [PubMed: 8721152]

16. Knudsen EI, Cohen YE, Masino T. Characterization of a forebrain gaze field in the archistriatum of the barn owl: microstimulation and anatomical connections. J Neurosci 1995;15:5139-5151. [PubMed: 7623141]

17. Stanton GB, Goldberg ME, Bruce CJ. Frontal eye field efferents in the macaque monkey: II. Topography of terminal fields in midbrain and pons. J Comp Neurol 1988;271:493-506. [PubMed: 2454971]

18. Bruce CJ, Goldberg ME, Bushnell MC, Stanton GB. Primate frontal eye fields. II. Physiological and anatomical correlates of electrically evoked eye movements. J Neurophysiol 1985;54:714-734. [PubMed: 4045546]

19. Dias EC, Segraves MA. Muscimol-induced inactivation of monkey frontal eye field: effects on visually and memory-guided saccades. J Neurophysiol 1999;81:2191-2214. [PubMed: 10322059]

20. Knudsen EI, Knudsen PF. Disruption of auditory spatial working memory by inactivation of the forebrain archistriatum in barn owls. Nature 1996;383:428-431. [PubMed: 8837773]

21. Knudsen EI. Auditory and visual maps of space in the optic tectum of the owl. J Neurosci 1982;2:1177-1194. [PubMed: 7119872]

22. Olsen JF, Knudsen EI, Esterly SD. Neural maps of interaural time and intensity differences in the optic tectum of the barn owl. J Neurosci 1989;9:2591-2605. [PubMed: 2746340] 
23. Cohen YE, Knudsen EI. Binaural tuning of auditory units in the forebrain archistriatal gaze fields of the barn owl: local organization but no space map. J Neurosci 1995;15:5152-5168. [PubMed: 7623142]

24. Harper NS, McAlpine D. Optimal neural population coding of an auditory spatial cue. Nature 2004;430:682-686. [PubMed: 15295602]

25. Reynolds JH, Chelazzi L. Attentional modulation of visual processing. Annu Rev Neurosci 2004;27:611-647. [PubMed: 15217345]

26. Motter BC. Focal attention produces spatially selective processing in visual cortical areas V1, V2, and V4 in the presence of competing stimuli. J Neurophysiol 1993;70:909-919. [PubMed: 8229178]

27. Spitzer H, Desimone R, Moran J. Increased attention enhances both behavioural and neuronal performance. Science 1988;240:338-340. [PubMed: 3353728]

28. McAdams CJ, Maunsell JH. Effects of attention on orientation-tuning functions of single neurons in macaque cortical area V4. J Neurosci 1999;19:431-441. [PubMed: 9870971]

29. Treue S, Maunsell JH. Attentional modulation of visual motion processing in cortical areas MT and MST. Nature 1996;382:539-541. [PubMed: 8700227]

30. Miller GL, Knudsen EI. Early visual experience shapes the representation of auditory space in the forebrain gaze fields of the barn owl. J Neurosci 1999;19:2326-2336. [PubMed: 10066282] 

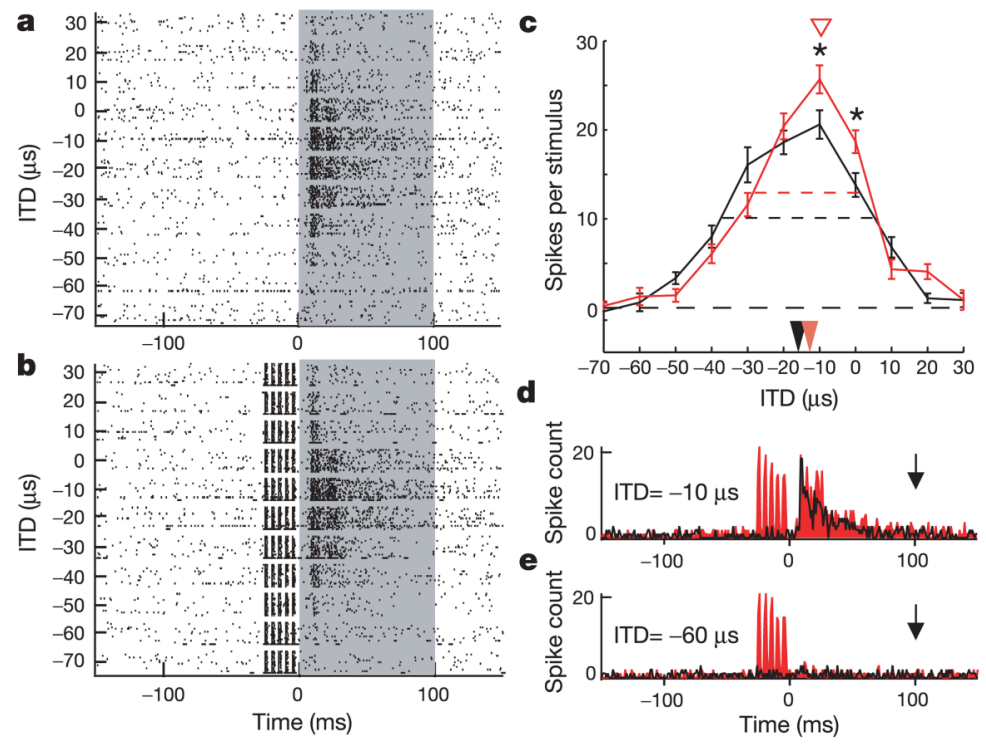

Figure 1. Effect of electrical microstimulation in the AGF on auditory responses at an aligned site in the optic tectum

a, Raster display of optic tectum auditory responses without AGF stimulation. Ordinate shows stimulus ITD; abscissa shows time relative to stimulus onset; shaded area shows duration of auditory stimulus and the post-stimulus time-window used for data analysis. Best ITD - 16 $\mu \mathrm{s}$; tuning width at half-max $42 \mu \mathrm{s}$. b, Same as a, except that electrical microstimulation was applied to the AGF site immediately before the onset of the auditory stimulus. Vertical lines show an electrical stimulation artefact. Best ITD of the optic tectum site with AGF stimulation $-12 \mu \mathrm{s}$; tuning width at half-max $31 \mu \mathrm{s}$. c, Mean neuronal response plotted as a function of stimulus ITD for trials with (red) and without (black) AGF stimulation. Error bars represent s.e.m. Asterisk, $P<0.02$ (paired $t$-test). Solid arrowheads indicate best ITD with (red) and without (black) AGF microstimulation; open arrowhead indicates best ITD at the AGF site. d, Peristimulus time histograms of optic tectum responses to an auditory stimulus with an ITD of $-10 \mu$ s during trials with (red) and without (black) AGF stimulation. Arrow shows offset of auditory stimulus. e, Same as d, except histograms show responses to sound with an ITD of $-60 \mu$ s (outside the receptive field). Arrow shows offset of auditory stimulus. 

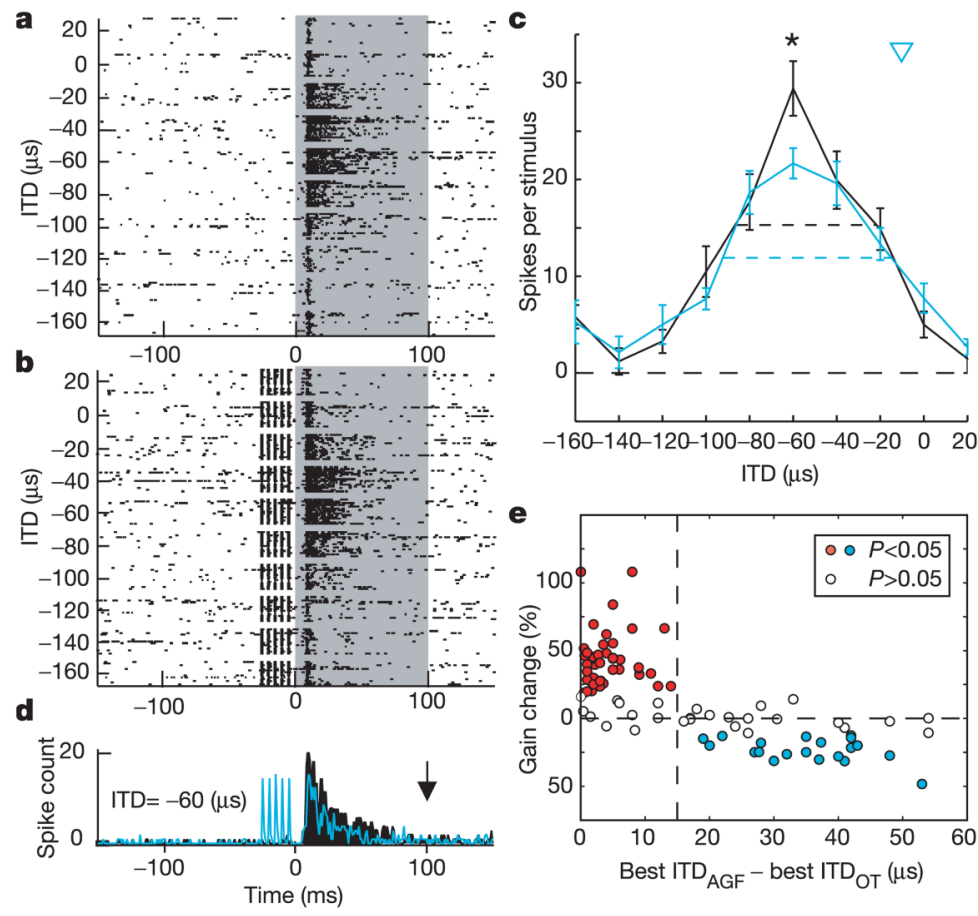

Figure 2. Effect of AGF microstimulation on a non-aligned site in the optic tectum The AGF site is the same as in Fig. 1 (best ITD - $10 \mu \mathrm{s}$ ). For a-d, the conventions are as described in Fig. 1. a, Raster display for trials without AGF microstimulation. Best ITD - 55 $\mu \mathrm{s}$, tuning width $64 \mu \mathrm{s}$. b, Raster display for trials with AGF stimulation (7 $\mu \mathrm{A}, 25-\mathrm{ms}$ train, $200 \mathrm{~Hz}$; current to evoke eye saccades $175 \mu \mathrm{A}$ ). Best ITD $-55 \mu \mathrm{s}$, tuning width $77 \mu \mathrm{s}$. c, Mean responses as a function of ITD for trials with (blue) and without (black) AGF stimulation. Error bars represent s.e.m. Asterisk, $P<0.03$ (paired $t$-test). Open arrowhead shows best ITD at the AGF site. d, Peristimulus time histograms of optic tectum responses to ITD $-60 \mu$ s with (blue) and without (black) AGF microstimulation. Arrow shows offset of auditory stimulus. e, The effect of AGF microstimulation on optic tectum responses depends on the alignment of AGF and optic tectum tuning. Ordinate shows gain change at each optic tectum site; abscissa shows the difference between ITD tuning of the AGF and optic tectum sites. Filled symbols, $P<0.05$; open symbols, $P>0.05$ with current levels up to $40 \mu \mathrm{A}$. Vertical dashed line indicates best ITD $_{\text {AGF}}-$ best ITD $_{\mathrm{OT}}=15 \mu \mathrm{s}$. 
a

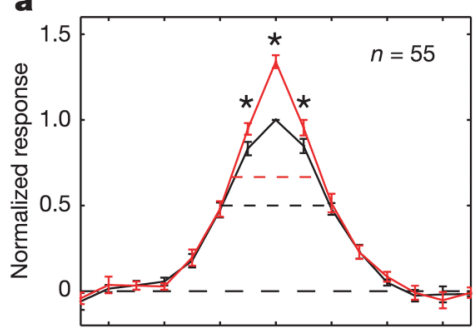

C

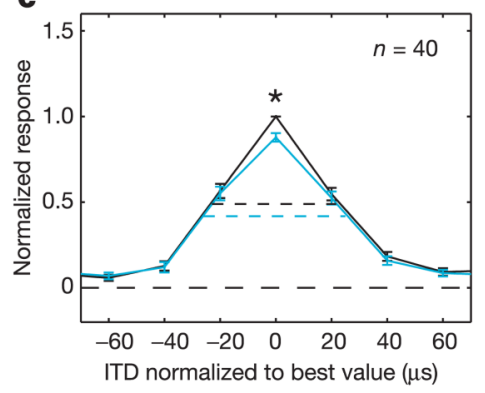

b

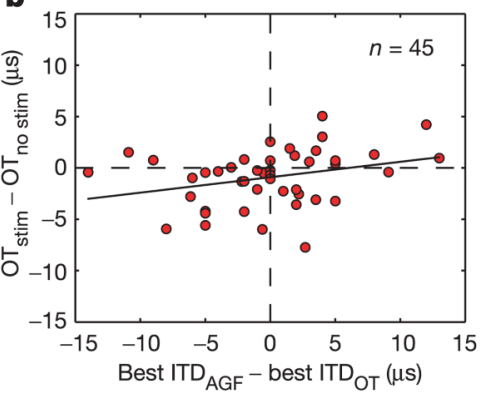

Figure 3. Summary of the effects of AGF microstimulation on auditory responses in the optic tectum a, Population ITD tuning curves for aligned pairs $(n=55)$ measured with (red) and without (black) AGF microstimulation. Population tuning curves were constructed by normalizing the mean response at each optic tectum site to the maximum mean response for that site without AGF stimulation. All tuning curves were aligned according to their best value (plotted as ITD $0 \mu \mathrm{s})$ and averaged. Error bars represent s.e.m. Note that here, AGF best ITDs were to either side of optic tectum best ITDs. Dashed lines indicate width at half-max. Asterisk, $P<0.01$ (paired $t$-test). b, Shift in optic tectum tuning induced by AGF microstimulation $\left(\mathrm{OT}_{\mathrm{stim}^{-}}\right.$ $\mathrm{OT}_{\text {nostim }}$ ) was positively correlated with the difference in ITD tuning between the AGF and

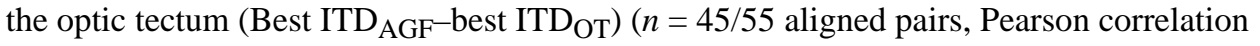
coefficient $r=0.3, P<0.05$, two-tailed Student's $t$-test). c, Same as a, except that the tuning curves are based on data collected from non-aligned pairs $(n=40)$. Error bars represent s.e.m. Asterisk, $P<0.01$ (paired $t$-test). 